\title{
Zippo Case Study: Where Have All The Smokers Gone?
}

Kathleen M. Premo, St. Bonaventure University, USA Darwin L. King, St. Bonaventure University, USA

\begin{abstract}
The primary subject of this case concerns Zippo Manufacturing Company, the company famous for its Zippo windproof lighters with their lifetime guarantee and the distinctive "click" when opened. Today, the company continues to manufacture and sell lighters from its main facility located in Bradford, Pennsylvania. The company has expanded into the production of highquality hunting, pocket, and utility knives as a result of the purchase of W.R. Case \& Sons and, through a subsidiary, Zippo Fashion Italia S.r.l., it sells leather products. This case presents an historical development of the firm taking it to its current day position and noting current challenges and future opportunities facing the company. A secondary issue confronting Zippo involves changes in American culture that have affected this company; more recent issues for Zippo include problems related to the Department of Transportation's rule governing the shipment of hazardous materials and problems resulting from the manufacture of cheap knockoff lighters being produced in China. This case was written for use in a Strategic Management class.
\end{abstract}

Keywords: Zippo, Manufacturing, Lighters, International Business, Lighter Collectors

\section{INTRODUCTION}

$\int$ ippo Manufacturing Company celebrated its 75th anniversary in July of 2007, noting that nearly 450 million pocket lighters had been manufactured in Bradford, Pennsylvania as of that date (Olean Times Herald, July , 2007; p. 3). But, much has happened to get Zippo to this point. The history of the Zippo Manufacturing Company can be traced back to 1932 when an industrious, young entrepreneur, George G. Blaisdell put together his first famous windproof lighter above his garage in Bradford, Pennsylvania (www.zippo.com). Blaisdell who had obtained rights to an Austrian windproof lighter that had a removable top, redesigned the lighter so that it would be good looking and easier to use. The lighters were "windproof" since they stayed lit, even in gusty weather, as a result of the unique design and the appropriate rate of fuel delivery. Blaisdell named the improved product "Zippo" because he liked the name zipper - a product manufactured in a nearby Pennsylvania town (Zippo/CaseMuseum). He received a patent on March 3, 1936 and shortly thereafter began retailing Zippo lighters for \$1.95/ unit (www.zippo.com). The basic design remains virtually unchanged from that time and Bradford, Pennsylvania continues to be the manufacturing center for lighters and sundry products. Today, Zippo is considered an American icon; there is an enviable $95 \%$ awareness of the product and, since the product is made in the USA, it has a worldwide appeal factor (www.zippo.com).

\section{ZIPPO MANUFACTURING COMPANY}

During World War II, the Zippo lighter became a patriotic symbol of the war. It is interesting that during that time, lighters could be purchased at Army PXs but the lighters were not available for sale to civilians. Also, because brass was restricted for military use, the lighters manufactured during this time were crafted of a low-grade steel and spray painted black (Meabon, p. 32).

On September 3, 2003, Zippo celebrated the production of the 400th million windproof lighter (Zippo/CaseMuseum). To put this number in perspective, Zippo continues to produce about 13 million lighters in 
Bradford, Pennsylvania each year or about 50,000 lighters each day. The Zippo lighter division distributes products to consumers in approximately 120 countries worldwide (www.zippo.com). The Company dominates the refillable lighter business with an enviable two-thirds market share. In 2001, just over $20 \%$ of American adults were smokers, according to the Centers for Disease Control (Inc. 2004; p. 42). A healthy international business accounts for about $60 \%$ of its sales; of particular note is the fact that approximately $20 \%$ of Zippo lighters produced today are exported for sale in Japan (Zippo/Case Museum). Studies indicate that $21 \%$ of the owners of Zippo lighters are collectors (Zippo/Case Museum); thus, even in the United States where the number of smokers has diminished in recent years, the sales of Zippos remain strong because of sales to collectors. Collectors are a significant factor in terms of sales; there are millions of collectors in the US and 12 lighter collector clubs are located around the globe (www.zippo.com). The primary target market for the Zippo products has been identified as the 18-24 age group (Zippo/CaseMuseum).

Currently, the Zippo Repair Clinic located in Bradford, Pennsylvania employs skilled technicians who do everything possible to repair the original lighter returned by an owner. A broken hinge, which takes the bulk of the wear, is the most common repair need. One-quarter million repairs are handled every year through the Bradford facility (Zippo/CaseMuseum).

\section{ZIPPO CORPORATE STRUCTURE AND PRODUCT LINES}

The corporate structure includes Zippo Manufacturing Company, W.R. Case \& Sons (the knife division) and Zippo International that includes Zippo UK, Zippo Europe and Zippo Fashion Italia (Zippo/CaseMuseum).

Today, the control of the Zippo Company remains in the hands of private owner and Chairman of the Board, George B. Duke who is a grandson of founder Blaisdell. Gregory W. Booth is the current President and CEO of Zippo Manufacturing Company (www.zippo.com). The Zippo windproof lighter debuted in 1933, but 27 years earlier, J. Russell Case and Harvey Platts incorporated their business in Pennsylvania as W.R. Case and Sons Cutlery Co. and located in Bradford. For a period of time (1972- 1993), W.R. Case and Sons Cutlery Co. was sold to American Brands, Inc. But in 1993, Zippo acquired Case and controls the company today (www.zippo.com). W.R. Case \& Sons Cutlery Co. is known for its quality pocketknives and remains competitive in that business (Meabon, p. 110). The knife business makes up approximately $20 \%$ of the overall parent company income (Zippo/CaseMuseum).

In 2004, the Zippo Company acquired an Italian company that manufacturers a fine line of Italian handbags and leather products, retailed under the name of Zippo (www.zippo.com). The strategy behind this purchase came from a desire to protect the Zippo trademark. Prior to the purchase of Zippo Italia, the original leather goods company had registered the Zippo trademark in Italy but could not sell products in the rest of Europe. Zippo Manufacturing Company's purchase of Zippo Italia not only serves to protect the Zippo name in Italy but also enables Zippo Italia products to be retailed in the remainder of Europe. Today, this Zippo product line's sales in Europe are strong yet the only venue where a Zippo Italia product can be purchased in the U.S. is in the Zippo/CaseMuseum Visitors Center in Bradford, Pennsylvania.

Zippo products manufactured in Bradford today include lighters, wallets, tape measures, pocketknives, money clips, writing instruments, and key holders. A few other products have been tested and briefly retailed by Zippo. Flints and fuel for the lighters are two important key products for Zippo and are made today at the Congress Street facility in Bradford, Pennsylvania (Meabon, p. 97).

Case employs approximately 360 employees in the U.S. and Europe. Domestic sales account for $95 \%$ of Case's business; $5 \%$ of production is exported. Many of the subsidiary's cutlery products are purchased and held as collectibles (Zippo/CaseMuseum).

In 2002, Zippo introduced the Multi-Purpose Lighter, which is a refillable butane utility lighter. Zippo also introduced its Z-series lighter that is produced from unique materials and has been planned for a limited-production run. In July of 2005, Zippo introduced the Mini MPL, a smaller scale refillable butane lighter. As a change from the 
traditional Zippo products, this product is manufactured in China (Zippo/CaseMuseum). The newest products include leather wallets, lighter pouches, cigarette cases, ID card cases (made in Italy) as well as new lighters (Zippo/CaseMuseum). It is important to note that the lure of the lighters and cutlery products as collectables is significant to the overall current success of Zippo.

The Chinese retail market for lighters appears attractive because of the vast number of consumers and the propensity of that population to use tobacco products (the distinctive lighters that shut with a click are popular in Brazil, Russia and especially China, where a third of the world's smoking tobacco gets lit) (Forbes, p. 103). Russia may offer a strategic market for Zippo in the near future. Playboy, Phillip Morris and Harley Davidson have been identified as companies that may provide future growth opportunities in terms of joint ventures in retailing Zippo leather goods. In late 2004, new camping/hiking lighters were introduced. Zippo is steering the course by planning to diversify its manufacturing. Management of the company realizes the importance of innovation for future growth; plans for future growth include doubling the size of the company by 2010 (Inc., September, 2004; p. 44). Leadership focuses on product integrity, the importance of building upon customer loyalty and stressing brand value. The correct marketing enhanced by a strong public relations effort is critical for its sustained success.

The major marketing theme is the famous "lifetime guarantee" that accompanies every lighter. Certainly, the intrinsic part that the Zippo lighter played during World War II as well as the Korean and Vietnam Wars added to the demand for the lighter during that era. The "sound" experience of the lighter made by opening and closing the top, is always the same and gives instant identification. In 2001, Zippo officially abandoned the strategic mindset of one-product manufacturing business and entered the 21st century world of brand management (Inc., September 2004; p.43). Since 2002, the company has sponsored "Zippo Click" (zippoclick.com) where Zippo enthusiasts can interact with other Zippo fans. Collecting has become a hobby and even a business for many people. Currently, Zippo employs a worldwide sales staff that handles international sales.

The current Zippo strategy includes the approach of "doing it right the first time" in order to increase efficiency. Also, in a plan to increase efficiency, the company hopes to make more lighters while employing fewer employees. Short-term growth of the lighter business is predicted to be shallow so Zippo is planning to expand into other product lines. Zippo management plans to diversify so that half of its sales will be in non-smoking products. Duke, and his top manager, CEO Greg Booth, have set an ambitious goal: by 2010, to derive half the company's revenue from products unrelated to tobacco (Inc., September, 2004; p.44). Current products include a multi-purpose lighter (MPL), a mini MPL, the outdoor utility lighter (OUL), the Zippo Hand Warmer, and the newest line of Zippo butane gas lighters which the company claims is the next step in the evolution of the perfect flame (Zippo/Case Museum). Zippo has licensed the Zippo name in China, Japan, and Italy, for use on stoves, clothes, watches, and sunglasses. Sales in China have doubled, to $\$ 10$ million, since 2003 (Inc., September, 2006; p. 48). They're setting out to more than double current revenue over the same period (Ibid). Officers of the corporation remain dedicated to protecting the brand. These leaders recognize the importance of succession planning and have identified people who could be promoted tomorrow - if necessary. It should be noted that the current manufacturing facility is staffed by a dedicated, quality workforce and the location of the facility is in rural, northern Pennsylvania where wages are depressed which has contributed to the financial success of the operation.

\section{PROBLEMS AND THREATS}

Counterfeit Zippo-style lighters have sprung up throughout the world, particularly in the Far East where lighters have been cheaply produced in China. Zippo continues to take aggressive measures to meet this problem. Management has indicated that from the period between 1995 and 2001, Zippo's business was reduced by one-third and a big piece of that was (a result of) counterfeiting overseas (Forbes, p. 102). Ancillary problems that are associated with this counterfeiting include customers being injured by a fake lighter carrying Zippo's name and later, turning around and attempting to sue Zippo for the defects. Similar problems have been identified with Zippo lighter fuel (Bradford Era, 2004; p. 2). Another problem is that some of the counterfeit lighters carry pornographic or other inappropriate designs which are damaging to the Zippo image. Although not legally responsible for these problems associated with the counterfeits, the negative publicity and the expense of investigating allegations is a 
concern for Zippo (Bradford Era, 2004; p.2). The flint, a critical element for operation of the lighter, can be problematic too; the Zippo flint tends to wear out relatively quickly.

An advantage that Zippo holds is an extensive positive awareness of the product, yet it is an uphill battle to maintain this $95 \%$ recognition awareness level and it is always a challenge to protect the brand name (Olean Times Herald, July, 2007, p.2). Even though the purchase of the Zippo leather goods business deal seemed like the best decision in order to protect the Zippo name, the products are better known in Europe, and going head-to-head with competitively priced purses/leather products in the U.S. may be an overwhelming challenge.

In early 2005, Zippo was met with a potentially disastrous federal regulation The Transportation Security Administration (TSA) had ruled in March 2005 that unfilled lighters would be banned in checked luggage on U.S. airliners (www.zippo.com). Company officials and local politicians lobbied for a change. However, in mid May of 2005, the TSA changed that rule so that lighters without fuel would be permitted in checked baggage. Lighters with fuel are still prohibited in checked baggage, unless they adhere to the Department of Transportation (DOT) exemption, which allows up to two fueled lighters if properly enclosed in a DOT approved case (www.tsa.gov). If the earlier rule had not been rescinded, the impact on company business could have resulted in a decline in sales by as much as $30 \%$. The earlier rule would have barred collectors from flying with their collections to swap meets even if their lighters were not filled. As of the summer of 2007, the TSA removed the ban on common lighters in the cabins of our nation's airplanes (www.tsa.gov). This was a significant win for Zippo but the battle has been financially costly for the company.

Zippo Manufacturing Company along with its subsidiaries is a privately held organization. Financial statements are therefore not publicly available. The following proposed statements were prepared by the authors to be used in analyzing the company. They were created for this purpose only and do not represent actual Zippo financial data. All figures are in thousands of dollars.

\section{Zippo Manufacturing Company Consolidated Balance Sheet}

For Years Ended December 31, 2007 and 2006

Assets

Current Assets:

Cash and cash equivalents

Accounts and notes receivable (less

allowances for doubtful accounts)

Merchandise Inventory

Prepaid Expenses

Total Current assets

\section{Property, plant and equipment:}

Land

Buildings

Less: Accumulated Depreciation

Factory machinery and equipment

Less, accumulated depreciation

Property, plant and

Equipment, net of depreciation

Other assets including patents

Total assets $\underline{2007}$

$\$ 3,206$

8,985

15,567

$\underline{1,268}$

$\$ 30,026$

$\$ 7,689$

$\$ 45,987$

$\underline{42,645}$

$\$ 26,843$

$\underline{24,672}$

\section{3,333 \\ $\underline{2,171}$ \\ $\$ 13,193$ \\ $\underline{1,254}$}

$\$ 44,473$ $\underline{2006}$

$\$ 4,964$

5,843

8,879

$\frac{1,006}{\$ 20,692}$

$\$ 7,689$

$\$ 45,987$

$\underline{41,876} \quad 4,111$

$\$ 26,793$

$\underline{24,065}$

$\underline{2,728}$

$\$ 14,528$

$\underline{1,487}$

$\$ 36,707$ 


\section{Liabilities \& Stockholder's Equity}

\section{Current Liabilities:}

Accounts Payable

Notes payable ( $<1$ year)

Current portion of long-term debt

Total current liabilities

Long-term Liabilities

Notes payable (> 1 year)

Mortgage payable

Total long-term liabilities

Total Liabilities

Stockholder's Equity:

Capital Stock/Paid-in Capital

Retained Earnings

Total Stockholder's Equity

Total liabilities and owner's equity

$\begin{array}{rr}\$ 8,765 & \$ 6,432 \\ 5,000 & 2,700 \\ 7,500 & 4,400 \\ \$ 21,265 & \$ 13,532\end{array}$

$\$ 6,400$

$\underline{1,500}$

$\$ 7,900$

$\$ 29,165$

$\$ 10,000$

$\underline{5,308}$

$\$ 15,308$

$\$ 44,473$
$\$ 8,400$

$\$ 10,200$

$\$ 23,732$

$\$ 10,000$

$\underline{2,975}$

$\underline{\$ 12,975}$

$\$ 36,707$

\section{CONCLUSION}

After studying Zippo, it may appear that the company is caught in a time warp. Its employees and residents of the city take great pride in Zippo's history and the memories of past successes. George Duke's determination to keep Zippo local and family owned may be another impediment to the company's future growth. Quality products continue to be made at Zippo but the overall consumer market continues to diminish for tobacco related products- especially in the U.S. Although the Chinese and Russian retail markets for lighters appear attractive, Zippo's strategy to increase efficiency by making more lighters while employing fewer employees is questionable. Unfortunately, the company's management focus for the past few years has been directed at addressing problems with the TSA and in defending its patent rights with the unscrupulous Chinese manufacturers making cheap knock offs. Efforts of management have been directed toward those concerns while the day-to-day manufacturing has continued with little focus on the 2010 company goal of doubling the size of the company. Zippo desperately needs to be energized and despite its published plans, Zippo continues to produce too many products that are tobacco centered. Depending on sales to collectors for continued business may prove disastrous in the current economy when people are curtailing their spending on non-essential items. And as for more bad news, published reports in the summer of 2008 have noted a significant layoff of Zippo's employees at its main manufacturing facility in Bradford, Pennsylvania.

\section{REFERENCES}

1. Mandak, J. (2005). A. Win for Zippo. Olean Times Herald, 17 May, 2005.

2. Meabon, Linda L. (2003). Images of America: Zippo Manufacturing Company. Charleston, SC: Arcadia Publishing.

3. Neuborne, Ellen. The Problem: Zippo has a strong brand name, but stagnant sales. Can the fabled firm market its way of the doldrums? Inc., September 2004 (Vol.26 Issue 9).

4. Olean Times Herald, Zippo/Case Swap Meet Will Bring Collectors to Bradford July 16-17, May 27, 2004.

5. Olean Times Herald, Zippo means a lot to the community..., July 28,2007.

6. $\quad$ Orr Deborah, Pirate's Ball. Forbes, April 9, 2007 (Volume 179, Issue 7).

7. Sauer, Patrick J., Firing Up Sales, Inc., September 2006 (Vol. 28, Issue 9). 
8. Schellhammer, M. (2004), Counterfeiting of Zippo Lighters in China Affecting Bradford, The Bradford

Era., August 3, 2004.

9. TSA (2008), Home page, Retrieved March 24, 2008 from http://www.tsa.gov/travelers/airtravel/prohibited/permitted-prohibited-items.shtm.

10. Zippo (2008), Home page. Retrieved March 24, 2008 from http://www.zippo.com.

11. Zippo/CaseMuseum (2008).

\section{AUTHOR INFORMATION}

Kathleen M. Premo is a Lecturer in the School of Business of St. Bonaventure University. She has just completed her eleventh year of teaching at that institution. One of the areas that she teaches is Business Policy/Strategic Management and uses many cases in teaching that course. She is a native of South-Western New York State and lives a short drive from Bradford, Pennsylvania which is home to Zippo Manufacturing Company.

Darwin L. King is a Professor of Accounting at St. Bonaventure University. He is a veteran of twenty-five years of teaching at St. Bonaventure. Professor King, a Certified Public Accountant, is a native of Michigan. He has published extensively in the area of timber accounting and taxation. He has published numerous articles dealing with the historical aspects of the development of accounting. He is an avid collector of original accounting documents that date back to the Civil War.

\section{TEACHING NOTES}

Included in this section are questions that have been prepared by the authors. These questions are appropriate for use of students in analyzing and preparing the case for class discussion.

\section{Questions for the Zippo case:}

1. Since Zippo Manufacturing Company does not appear to have a vision or mission statement, prepare a vision statement that will address where the company hopes to be in the future and also, prepare a mission statement that will identify the scope of Zippo's operations.

\section{Proposed Vision Statement}

To continue to be the premier manufacturer and distributor of quality lighter products, cutlery, and leather products in the world.

Proposed Mission Statement

Zippo Manufacturing Company is dedicated to producing quality personal lighters, knives through our subsidiary, Case Cutlery, and quality leather products through our Italian subsidiary, Zippo Italia. Our company, headquartered in Bradford, Pennsylvania directs products to a worldwide customer base, mindful of the importance of the collector audience while dedicated to providing a quality product to all our consumers throughout the world. We strive to remain technologically current with up-to-date equipment that is manned by staff trained to produce quality products. Our major competitive advantage is the identification of our products with quality and our guarantee, "It works or we'll fix it free." We at Zippo are committed to our community in which we operate and recognize the important of our employees as valuable assets of the firm. We are driven to continually improve the quality of our products while adding or deleting products in our line in order to meet the changing needs of our consumer with a focus on remaining financially sound and providing value to our consumers.

2. Since Zippo's management realizes the importance of innovation for future growth, and given the problems that Zippo is experiencing with fewer and fewer people in the U.S. smoking, what would you suggest as a direction (and what areas other than lighters, knives, leather goods) for this company to pursue for innovation? 
Students' suggestions can vary. Manufacturing products that would require metal casings might be a good match for Zippo; quality garden tools might also be a good alternative for Case to pursue.

3. Zippo's upper management plans to diversify by 2010 so that half of its sales will be non-smoking products. Are there products/companies that you would suggest that Zippo should consider acquiring? What about joint ventures?

Interest rates and costs of an acquisition are factors that should be considered especially since Zippo is a privately owned company. A small ammunition company needing metal casings might be considered a good acquisition or a joint venture possibility.

4. Is the W.R. Case \& Sons portion of its business compatible with the Zippo lighter business? Is the knife business too competitive domestically? What could be done to increase international sales of its knife products?

The advantage of the Zippo/Case business is that both facilities are located in the same small Pennsylvania city. Even though the Case business is well known in Northern Pennsylvania, the knife business is competitive domestically. The products produced at the Case facility are quality products. Perhaps a more prudent strategy might be to use an aggressive market penetration into Canada especially since it is close to the Case production facility.

5. Given the background information in the case, do you feel that the purchase of the Zippo leather products, the Zippo Fashion Italia line, was the proper decision for Zippo? What should Zippo do to enhance sales of this line? Would you suggest that the line be sold to another company that would then be required to use a different brand name?

The acquisition of Zippo Fashion Italia seemed like an odd acquisition for Zippo Manufacturing Company. Sales of this product line are doing well in Europe where the name is better known. It would seem that in order to raise capital to expand production facilities in Bradford, it may be worth considering the sale of this part of the operation.

6. Do you feel that Zippo should consider moving from the Bradford, Pennsylvania headquarters? What factors should be considered in this decision?

Labor costs are relatively affordable in this rural community and the company's employees are known for quality work. Another consideration is the cost of opening a manufacturing operation in Asia. Zippo is still a privately owned company; the cost of setting up operations abroad could be expensive for the Duke family.

7. Should Zippo move its manufacturing of lighters abroad considering the company's concern for keeping manufacturing and its associated labor costs under control AND the fact that international sales are strong? If so what country/ countries in addition to China should Zippo's manufacturing expand into?

Rather than completely moving operations to an Asian country to take advantage of cheap labor, Zippo might consider opening a smaller international manufacturing facility in Asia since Zippo considers that the market for smokers is so defined (presently) in this area of the world. It is always worth considering the advantages of manufacturing close to your customers. Zippo should target areas in the world where smoking is pervasive and where people are willing and able to pay the equivalent of $\$ 25$ American for a lighter.

8. Make some suggestions for enhancing the marketing efforts of Zippo. Should these efforts be directed more at international markets?

With 2 out of 3 people in China smoking, that market looks promising for increased marketing penetration. Russia and Turkey might also be countries to aggressively market. 
9. Since the collectible business has become so important for sales for Zippo, and based on the case you read, is Zippo doing enough to promote this part of its business?

With decreasing interest in smoking in the U.S., Zippo should step up sales of its collectible business. Frequent contact with Click members, frequent Internet promotions of collectibles may increase business.

10. Should Zippo promote more aggressively via the Internet? Why or why not?

Zippo should certainly continue to make its product available via the Internet and make better use of Internet promotions. The Internet is a relatively inexpensive way to market products.

11. It was indicated in the case that Zippo has had some success with joint ventures (Playboy, Phillip Morris, Harley Davidson). Can you identify a few other companies that might be a good match for this type of business arrangement so both that company and Zippo could benefit?

Successful tobacco companies might be a good match-Altria, UST (cigars). Other student answers could vary.

12. The information provided in the case indicated that Zippo has an enviable 95\% product awareness and also that the primary target market for Zippo products has been identified as the 18 to 24 year age group. How can Zippo be more successful in reaching this particular target market? to maintain that high level of product awareness where it is so important for sales?

Zippo might try ads in conjunction with NASCAR; Zippo might try to advertise more during sporting events and during Harley Davidson rallies.

13. Identify strengths and weaknesses of Zippo. Explore external threats and opportunities for future growth/existence.

Strengths:

a. Zippo is an American icon

b. worldwide name recognition

c. lifetime guarantee

d. sound company leadership

e. Zippo Click groups interested in collectibles

f. dedicated employees

g. strong international sales

Weaknesses:

a. no mission statement

b. privately held company

c. lighters/cutlery only manufactured in Bradford, PA

$d$. increasingly expensive to manufacture

e. Zippo lighters cost more than BIC lighters/matches

f. can be a problem to move product i.e. lighter fuel, on aircraft

g. $\quad$ relatively limited product line (lighters, knives and leather products)

h. social stigma directed at those people who smoke in most parts of the U.S.

Opportunities

a. one in three Chinese smoke

b. areas of the world outside the U.S. where smoking is popular

c. Chinese economy is improving

$d$. cheaper areas of the world were Zippo can manufacture

$e$. low interest rates which may encourage another timely acquisition

$f$. increasing interest in the Internet as a venue for increasing sales 


\author{
Threats \\ a. fewer people smoking today in the U.S. \\ b. competition - cheap lighters; cheap knives; better known leather lines in the U.S. \\ c. Chinese knock offs continue to spring up \\ d. lawsuits \\ e. not "cool" to smoke in the U.S. \\ f. government regulation of fuel producing business \\ g. a struggling economy
}

Review the Balance Sheet for Zippo that is included in the case and answer the following questions:

14. The current assets of Zippo increased significantly from 2006 to 2007 which is normally a positive event. In this situation, what problems do you see for Zippo related to the increase in current assets?

Students should be able to point out several problems with this increase in current assets.

First, although the total current asset figure increased, cash and cash equivalents decreased by more than 1.75 million (35\%). This may cause problems in the future with payment of current liabilities which increased by $75 \%$ (nearly 7 million). This huge build up of inventory probably indicates a significant drop in sales. Excess inventories may result in the layoff of employees in the near future. Third, accounts receivable increased by nearly 54\% (over 3 million). This indicates that Zippo's customers are not paying their bills in a timely fashion. This will no doubt cause cash flow problems in the near future. Fourth, the prepaid expenses also increased which may be an indicator that Zippo had to prepay items (rent, insurance, taxes, etc) due to vendor demands. In total, the current asset changes from 2006 to 2007 signal significant problem areas that must be addressed by management.

15. Review the plant, property, and equipment section of the Balance Sheet. What do these figures tell you about the assets of Zippo? What problems may this cause in the future?

Students will likely recognize that the buildings, machinery, and equipment of Zippo are quite old. They are nearing the point where they are fully depreciated and the firm will no longer benefit from depreciation expense deductions. For example, the buildings are $92.7 \%$ depreciated in 2007. Likewise, the machinery and equipment have been depreciated $91.9 \%$ of their historical cost basis. In addition to running out of depreciated deductions, the firm will likely have to spend significant funds to maintain and improve the old buildings and purchase modern machinery and equipment which should improve its efficiency. Overall, the fixed asset section of the Balance Sheet points to a number of potential problems.

16. Review the liability section of Zippo's Balance Sheet. What problems do you see? In particular, what is happening with current liabilities? Why is this a significant risk for the firm? What is happening to the total debt to equity ratio?

The information in the liability section of Zippo's Balance Sheet points to a number of additional problems. The total liabilities increase approximately 23\% fro 2006 to 2007. Most troublesome is the increase in current liabilities of 57\% (nearly 8 million dollars). This change combined with the decrease in cash and cash equivalents creates serious doubt that Zippo will be able to pay current liabilities in the next year. Students should realize that many of the long-term notes payable are maturing within the next year (two million of long-term notes have been moved to current status.) In addition, accounts payable increased by $36 \%$ probably as a result of decreasing cash and cash equivalents. The firm is delaying the payment of its accounts payable as a result of its customers delaying their payment of Zippo's accounts receivable. This "domino effect", if it continues, will significantly affect Zippo operations. The firm must attempt to speed collections of its customer' accounts receivables through efforts such as granting cash discounts (2/10 net 30) in order to be able to pay these increasing accounts payable on a timely basis. Overall, the changes in the liability section pose extremely serious potential problems for the firm.

17. Return to the liability section of the Balance Sheet. Assume that Zippo has a number of long-term notes payable at local banks that require Zippo to maintain a minimum current ratio (current assets/current 
liabilities) of at least 1.5, what if any, problems do you see? Be specific Also assume that the industry average current ratio is 1.75 . Evaluate this situation.

Students should be able to determine that in 2006, the current ratio $(20,692 / 13,532)$ was 1.529 . This was just above the requirement of the bank's loan agreement with the firm. If it were to decrease, which it did, the firm would be in violation of the loan agreement. In 2007, the current ratio decreased to $1.412(30,026 / 21,265)$ which violates the bank's requirements for the loans. The firm must address this situation since the bank (based on the loan covenant) may be able to call the entire loan and require immediate payment. The firm must attempt to increase the current ratio probably by decreasing its fast growing current liabilities. This may require additional long-term borrowing if accounts receivable collection can not be accelerated or stockpiled inventory can not be quickly sold. Since Zippo's current ratio in 2007 decreased to 1.412, it is significantly worse than the industry average of 1.75. It is a serious situation since the primary cause of the decrease in the current ratio was the exceptionally large increase in current liabilities. The problems of rapidly increasing current liabilities, uncollected accounts receivable, unsold merchandise inventory must be addressed by management immediately in order for Zippo to continue to operate as a "going concern." Students should be able to analyze the problem areas both in assets and liabilities.

\section{$\underline{\text { NOTES }}$}

